\title{
Efeito da idade e sexo sobre a concentração sérica de eritropoietina em equinos da raça Árabe ${ }^{1}$
}

\author{
Joandes Henrique Fonteque ${ }^{2 *}$, Aguemi Kohayagawa ${ }^{3}$, Mere Erika Saito ${ }^{2}$, Andrey \\ Borges Teixeira ${ }^{4}$, Marcos Jun Watanabe ${ }^{5}$ e Armen Thomassian ${ }^{6}$
}

\begin{abstract}
Fonteque J.H., Kohayagawa A., Saito M.E., Teixeira A.B., Watanabe M.J. \& Thomassian A. 2012. [Effect of age and gender about the serum concentration of eritropoetin in Arabian horses.] Efeito da idade e sexo sobre a concentração sérica de eritropoetina em equinos da raça Árabe. Pesquisa Veterinária Brasileira 32(Supl.1):21-24. Departamento de Medicina Veterinária, Hospital de Clínica Veterinária, Centro de Ciências Agroveterinárias, Universidade do Estado de Santa Catarina, Lages, SC 88520-000, Brazil. E-mail: fonteque@hotmail.com

The erythropoietin (EPO) is a glicoproteic grow factor synthesized by the adjacent cells in the proximal renal tubes and controlled by feedback mechanism that involve the tension of tissular oxygen. In the presence of low tension of arterial oxygen, the production of EPO increases and it causes a major production of erythrocytes in the marrowbone. Due to poor knowledge of the serum concentration of erythropoietin in equines and the absence of information about the differences between age and gender, the aim of this study was to compare the serum concentration of erythropoietin in Arabian horses, clinically healthy with different age and gender. A total of 31 horses were used from 6 to 12 months old (young) and over 24 months old (adult), 13 males (six young and seven adult) and 18 females (eight young and ten adult) clinically healthy. Blood samples were collected from jugular vein using a vacuntainer with blood clot gel activator and the serum was separated by centrifugation and stored until the time of processing. The EPO serum concentration was measured by radioimmunoassay method (RIA) using a commercial kit (EPO Trac TM ${ }^{125}$ I RIA, Diagnostic Systems Laboratories, Webster, Texas, USA). For statistical analysis of data were used the Student $t$ test at $5 \%$ level of significance $(P<0.05)$. It was not observed any statistic differences $(P<0.05)$ between the sex and age of the animals from 6 to 12 months old and over of 24 months. We concluded that the concentration of the EPO in Arabian equines is independent of the sex and age, and can be used as reference values however it is very important and necessary to obtain references values for each laboratory.
\end{abstract}

INDEX TERMS: Erythropoietin, Arabian, horses.

RESUMO.- A EPO é um fator de crescimento glicoprotéico sintetizado pelas células adjacentes aos túbulos proximais renais regulada via mecanismo de "feed back" envolvendo

\footnotetext{
${ }^{1}$ Recebido em 5 de junho de 2012.

Aceito para publicação em 24 de setembro de 2012.

${ }^{2}$ Departamento de Medicina Veterinária, Centro de Ciências Agroveterinárias, Universidade do Estado de Santa Catarina (UDESC), Lages, SC 88519-000, Brasil. *Autor para correspondência: fonteque@hotmail.com

${ }^{3}$ Departamento de Clínica Médica, Faculdade de Medicina Veterinária e Zootecnia (FMVZ), Universidade Estadual Paulista (Unesp), Rubião Júnior s/n, Botucatu, SP 18618-000, Brasil.

${ }^{4}$ Departamento de Radiologia Veterinária e Reprodução Animal, FMVZ-Unesp, Botucatu, SP.

${ }^{5}$ Departamento de Cirurgia e Anestesiologia Veterinária, FMVZ-Unesp, Botucatu, SP.
}

a tensão de oxigênio tissular. Na baixa tensão de oxigênio arterial, a produção de EPO aumenta causando uma maior produção de eritrócitos na medula óssea. Devido ao pouco conhecimento da concentração de EPO sérica em equinos e a ausência de trabalhos sobre o efeito da idade e sexo sobre a sua concentração o trabalho teve como objetivo comparar a concentração sérica de eritropoietina em equinos da raça Árabe de sexos e idades diferentes. Foram utilizados 31 equinos da raça Árabe, com idades de seis a 12 meses (jovens) e acima de 24 meses (adultos), sendo 13 machos (seis jovens e sete adultos) e 18 fêmeas (oito jovens e 10 adultas), clinicamente sadios. As amostras de sangue foram colhidas por venipunção jugular e o soro armazenado até o momento do processamento. A concentração sérica de 
eritropoetina foi determinada pelo método de radioimunoensaio (RIA) utilizando kit comercial (EPO Trac TM ${ }^{125}$ I RIA, Diagnostic Systems Laboratories, Webster, Texas, USA). Para análise estatística dos dados utilizou-se o Teste $t$ de Student ao nível de $5 \%$ de significância $(P<0,05)$. Não foram observadas diferenças significativas $(P<0,05)$ quando se compararam os animais divididos entre sexos e as idades de seis a 12 meses (jovens) e acima de 24 meses (adultos). Conclui-se que a concentração de eritropoietina em equinos da raça Árabe independe do sexo e idade, e pode ser utilizada como valores de referência, porém ressalta-se a necessidade da obtenção de valores de referência para cada laboratório.

TERMOS DE INDEXAÇÃO: Eritropoietina, equinos, Árabe.

\section{INTRODUÇÃO}

A massa eritrocitária é continuamente alterada de acordo com a sua função carreadora de oxigênio por um hormônio conhecido como eritropoetina (EPO) (Erslev 1991, D’Acunto et al. 2001). A EPO é um fator de crescimento glicoprotéico sintetizado pelas células adjacentes aos túbulos proximais renais (Erslev 1991, Geor \& Weiss 1993, Souillard et al. 1996a, Piercy et al. 1998) regulada via mecanismo de "feed back" envolvendo a tensão de oxigênio tissular. Na baixa tensão de oxigênio arterial, a produção de EPO aumenta causando uma maior produção de eritrócitos na medula óssea. 0 resultado é uma melhora no suprimento de oxigênio para os tecidos e posteriormente uma diminuição na produção da EPO (Lappin \& Maxwell 1997, McKeever et al. 2006). A EPO é o principal fator de regulação da proliferação das células progenitoras eritróides (Geor \& Weisss 1993, Scarth et al. 2011) e exerce seu efeito sobre as células alvo da medula óssea pela interação com receptores específicos na superfície celular. Na medula óssea, a EPO age sobre o compartimento de células progenitoras conhecido como células formadoras de colônia eritróide (CFU-E), multiplicando o número de células (Adamson 1996) e promovendo o seu desenvolvimento para eritrócitos maduros (Erslev 1991). Segundo Kearns et al. (2001) a sequência de aminoácidos da EPO permanece preservada entre os mamíferos, permitindo que anticorpos designados à determinação de EPO para pesquisas em humanos possam também ser utilizadas em outras espécies animais. Devido à escassez de trabalhos científicos sobre a concentração sérica de eritropoietina em equinos e a ausência de informações sobre as diferenças entre idades e sexo, o objetivo do trabalho foi comparar as concentrações séricas de eritropoetina em equinos da raça Árabe de sexo e idades diferentes.

\section{MATERIAL E MÉTODOS}

O estudo foi desenvolvido no Laboratório Clínico Veterinário "Aguemi Kohayagawa", Laboratório de Endocrinologia do Hospital Veterinário, Faculdade de Medicina Veterinária e Zootecnia da Unesp, Campus de Botucatu, SP, e no Laboratório de Farmacologia do Instituto de Biociências da Unesp, Botucatu, SP. Foram utilizados 31 equinos da raça Árabe, com idades de 6-12 meses (jovens) e acima de 24 meses (adultos), sendo 13 machos (seis jovens e sete adultos) e 18 fêmeas (oito jovens e 10 adultas), clinicamente sadios. Os animais eram mantidos em regime semi-intensivo com períodos de exercício leves diários. A alimentação constituiu-se à base de feno de coast-cross (Cynodon dactylon) e ração comercial concentrada, sal mineral e água à vontade. Os animais foram vacinados e vermifugados de acordo com o protocolo determinado para a propriedade. Foram colhidas amostras de $10 \mathrm{~mL}$ de sangue por venipunção jugular em tubos de colheita a vácuo com gel ativador de coágulo (Vacutainer, Becton \& Dickinson, England) e centrifugados a $1000 \mathrm{~g}$ para a obtenção do soro. As amostras de soro foram acondicionadas à temperatura de $-20^{\circ} \mathrm{C}$ até o momento do processamento. A concentração sérica de eritropoetina foi determinada pelo método de radioimunoensaio (RIA) utilizando-se kit comercial (EPO Trac TM ${ }^{125}$ I RIA, Diagnostic Systems Laboratories, Inc.) e a leitura realizada em contador gama (Cobra ${ }^{\mathrm{TM}} \mathrm{II}$ Auto-Gamma, Packard Instrument Company, Meriden). Para análise estatística dos dados utilizou-se o Teste $t$ de Student ao nível de 5\% de significância $(P<0,05)$ (Curi 1998).

\section{RESULTADOS E DISCUSSÃO}

A fisiologia dos eritrócitos nos equinos é única quando comparada a outras espécies animais. Eritrócitos imaturos contendo RNA (reticulócitos) são normalmente produzidos na medula óssea de equinos, mas não são liberados durante a homeostase ou nos casos de anemia leve a moderada (Coopers et al. 2005). Não foram observadas diferenças significativas $(P<0,05)$ quando se comparou os animais divididos entre sexos e as idades de 6-12 meses (jovens) e acima de 24 meses (adultos) (Quadro 1). De acordo com Jaussaud et al. (1994) os valores plasmáticos de EPO em 104 equinos clinicamente sadios, sendo 70 animais de corrida e 34 de esporte de ambos os sexos determinados pela técnica de

Quadro 1. Concentração sérica de eritropoietina (mUI/mL) em equinos da raça Árabe machos e fêmeas com idades de 6-12 meses (jovens) e acima de 24 meses (adultos)

\begin{tabular}{lcc}
\hline \multicolumn{2}{c}{ Categorias } & EPO (mUI/mL) \\
\hline Independente de idade & Macho & $5,19^{\mathrm{a}} \pm 2,29$ \\
Independente de sexo & Fêmea & $5,87^{\mathrm{a}} \pm 2,68$ \\
& Jovens (6-12 meses) & $5,36^{\mathrm{a}} \pm 1,96$ \\
Dependente de sexo e idade & Adultos (>24meses) & $5,77^{\mathrm{a}} \pm 2,93$ \\
& Machos & \\
& Jovens (6-12 meses) & $5,44^{\mathrm{a}} \pm 2,37$ \\
& Adultos (>24 meses) & $4,97^{\mathrm{a}} \pm 2,39$ \\
& Fêmeas & \\
& Jovens (6-12 mess) & $5,30^{\mathrm{a}} \pm 1,76$ \\
& Adultas (>24 meses) & $6,34^{\mathrm{a}} \pm 3,25$
\end{tabular}

${ }^{a}$ Para letras iguais não há diferença significativa $(p<0,05)$ entre os grupos.

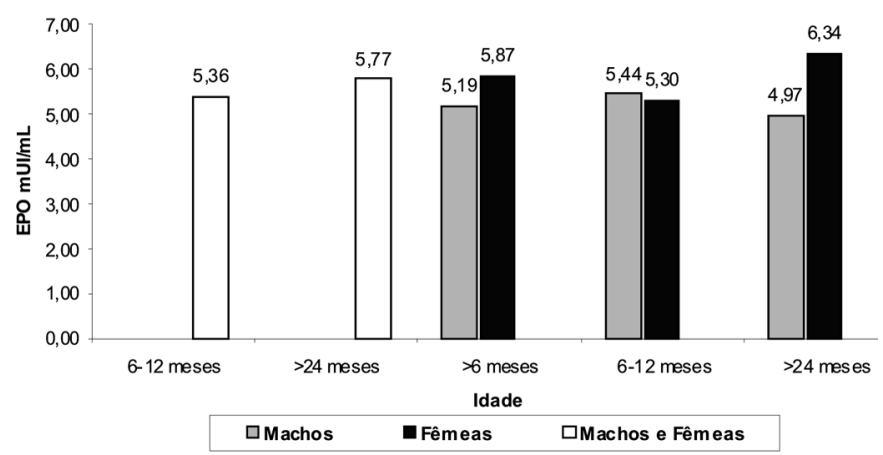

Fig.1. Distribuição da concentração de eritropoietina sérica (mUI/ $\mathrm{mL}$ ) de 31 equinos da raça Árabe machos e fêmeas com idades de 6-12 meses (jovens) e acima de 24 meses (adultos). 
radioimunoensaio foram $3,6 \pm 2,3 \mathrm{mUI} / \mathrm{mL}$, sendo que $65 \%$ das concentrações mensuradas encontravam-se entre $1,0 \mathrm{e}$ $4,0 \mathrm{mUI} / \mathrm{mL}$, e $98 \%$ entre 0,0 e $9,0 \mathrm{mUI} / \mathrm{mL}$. A média dos valores encontrados independentes de sexos e idades (Quadro 1 e Fig.1) foram superiores aos obtidos por Jaussaud et al. (1994), porém concordam com a observação de que a maioria dos animais $(93 \%)$ permaneceram entre as concentrações de 0,0 e 9,0 $\mathrm{mUI} / \mathrm{mL}$. Em estudos realizados por Garcia et al. (1982) e Rhyner et al. (1989) não foram observadas diferenças significativas entre sexos para as concentrações séricas de eritropoetina em humanos determinados pelo método de radioimunoensaio. McKeever (2002) relatou que o exercício agudo não estimula a elevação plasmática da concentração de EPO em equinos nem em humanos. E que a altitude causa uma elevação transitória na EPO plasmática em equinos e humanos, entretanto em equinos o aumento ocorreu somente durante as três primeiras horas do primeiro dia a 3800 metros de altitude (Wickler et al. 2000). McKeever (2002) concluiu que os equinos possuem uma habilidade inata para tolerar alterações agudas induzidas pelo exercício e altitude. Posteriormente, McKeever et al. (2010) observaram que a exposição dos equinos a altas altitudes aumentou a concentração de EPO em 387\% no primeiro dia. No entanto, $12 \mathrm{~h}$ mais tarde no segundo dia a EPO retornou aos valores normais pré-altitude. A concentração de EPO nos equinos não se alterou após oito dias em altas altitudes nem dois dias após ter retornado ao nível do mar. Além disso, não houve alteração da concentração de EPO em resposta ao exercício agudo ao nível do mar ou a altitude de 3800 metros. A eritropoietina recombinante humana (rhEPO) é comercializada para a utilização no tratamento da anemia, mas também tem sido utilizada em humanos e animais de esporte devido aos seus efeitos no aumento da resistência física (Reichel \& Gmeiner 2010). Segundo Guan et al. (2008) devido a capacidade da eritropoetina em estimular a produção de eritrócitos tem sido utilizada nos humanos e animais de esporte como doping sanguíneo ("blood dopping"). Porém, a administração de rhEPO em equinos está associada com o desenvolvimento de anemia não regenerativa e morte, como relatada por Piercy et al. (1998) e Woods et al. (1997). A anemia fatal imunomediada ocorre devido a produção de anticorpos contra a EPO endógena equina (McKeever et al. 2006). A anemia foi detectada em oito de 14 equinos que receberam rhEPO, sendo que cinco animais vieram a óbito. 0 risco do desenvolvimento de aplasia medular após a administração de rhEPO é baixo, porém a rhEPO administrada repetidamente aumenta muito o risco do desenvolvimento de anemia arregenerativa e morte. A anemia foi detectada entre duas semanas e quatro meses após a administração da última dose de rhEPO (Schwarzwald \& Hinchcliff 2004). De acordo com Souillard et al. (1996b) após uma única administração subcutânea de rHuEpo humana em equinos não houve alteração nos valores hematológicos, porém múltiplas e altas doses causaram alterações no eritrograma. Wen et al. (1993) sequenciou a eritropoietina em diversas espécies animais incluindo macaco Rhesus, rato, suíno, ovino, cão e gato e encontraram estrutura semelhante da EPO entre as espécies de mamíferos, tanto na sequência de aminoácidos como no cDNA. A EPO humana é 91\% homóloga a do macaco, $85 \%$ com a do gato e do cão, e 80 a $82 \%$ em outras espécies. Embora a sequência completa de aminoácidos da EPO equina não seja totalmente conhecida, existe aproximadamente $80 \%$ de semelhanças com a EPO humana. Em estudo realizado por Kearns et al. (2001) foi demonstrada reatividade cruzada entre os anticorpos anti-EPO humana e a EPO equina, permitindo que anticorpos designados para a determinação de EPO para pesquisas em humanos possam ser usados em outras espécies animais. As dosagens de EPO podem ser realizadas por técnicas de radioimunoensaio, porém outros testes como ELISA foram desenvolvidos para detecção rápida de rhEPO no plasma ou urina de equinos (Guan et al. 2008). A rhEPO também pode ser determinada pela cromatografia liquida acoplada a espectrometria de massa (LC-MS/MS) (Scarth et al. 2011). Mais recentemente, o método de micro-cromatografia WGA MAIIA foi desenvolvido para detecção de agentes estimulantes da eritropoiese na urina e plasma de equinos (Lönnberg et al. 2012).

\section{CONCLUSÃO}

Concluímos que a concentração de eritropoietina em equinos da raça Árabe independe do sexo e idade e pode ser utilizada como valores de referência, porém, ressalta-se a necessidade da obtenção de valores de referência para cada laboratório.

Agradecimentos.- Ao Prof. Dr. Ciro Moraes Barros do Laboratório de Farmacologia do Instituto Biociências (IB), e Dra. Eunice Oba Laboratório de Endocrinologia, FMVZ-Unesp, Botucatu, SP, e a equipe do Dr. Antonio Carlos C. Carneiro do Laboratório de Endocrinologia de Botucatu, SP.

\section{REFERÊNCIAS}

Cooper C., Sears W. \& Bienzle D. 2005. Reticulocyte changes after experimental anemia and erythropoietin treatment of horses. J. Appl. Physiol. 99:915-921.

Curi P.R. 1998. Metodologia e Análise da Pesquisa em Ciências Biológicas. Tipmic, Botucatu. 263p.

D’Acunto M., Limongelli F.M., Guerra G., Tafuri D., Fioretti L., Della Pietra A., Brancaccio P. \& Giordano-Lanza G. 2001. Erythropoietin: From the therapeutic use to the illicit use in sports. Medicina dello Sport 54(2):137144.

Erslev A.J. 1991. Erythropoietin. New Engl. J. Med. 324(19):1339-1344.

Garcia J.F., Ebbe S.N., Hollander L., Cutting H.O., Miller M.E. \& Cronkite E.P. 1982. Radioimmunoassay of erythropoietin: Circulating levels in normal and polycythemic human beings. J. Lab. Clin. Med. 99(5):624-635.

Geor R.J. \& Weiss D.J. 1993. Drugs affecting the hematological system of the performance horse. Vet. Clin. North Am., Equine Pract. 9(3):649-667.

Guan F., Uboh C.E., Soma L.R., Birks E., Chen J., You Y., Rudy J. \& Li X. 2008. Differentiation and identification of recombinant human erythropoietin and darbepoetin alfa in equine plasma by LC-MS/MS for doping control. Anal. Chem. 80(10):3811-3817.

Jaussaud P., Audran M., Gareau R.L., Souillard A. \& Chavanet I. 1994. Kinetics and haematological effects of erythropoeitin in horses. Vet. Res. 25(6):568-573.

Kearns C.F., Lenhart J.A. \& Mckeever K.H. 2000. Cross-reactivity between human erythopoietin antibody and horse erythropoietin. Electhrophoresis 21:1454-1457.

Lappin T.R.J. \& Maxwell A.P. 1997. Recombinant human erythropoietin and the anemic horse: Flogging a dead horse? Equine Vet. J. 29(4):255-256. 
Lönnberg M., Bondesson U., Cormant F., Garcia P., Bonnaire Y., Carlsson J., Popot M.A., Rollborn N., Råsbo K. \& Bailly-Chouriberry L. 2012. Detection of recombinant human EPO administered to horses using MAIIA lateral flow isoform test. Anal. Bioanal. Chem. 403:1619-1628.

McKeever K.H. 2002. The endocrine system and the challenge of exercise. Vet. Clin. North Am., Equine Pract. 18(2):321-353.

McKeever K.H., Agans J.M., Geiser S., Lorimer P.J. \& Maylin G.A. 2006. Low dose exogenous erythropoietin elicits an ergogenic effect in standardbred horses. Equine Vet. J. Suppl. 36:233-238.

McKeever K.H., Wickler S.J., Smith T.R. \& Poole D.C. 2010. Effects of high altitude and exercise on plasma erythropoietin in equids. Comp. Exerc. Phys. 7(4):193-199.

Piercy R.J., Swardson C.J. \& Hinchcliff K.W. 1998. Erythroid hypoplasia and anemia following administration of recombinant human erythropoietin to two horses. J. Am. Vet. Med. Assoc. 212(2):244-247.

Reichel C. \& Gmeiner G. 2010. Erythropoietin and analogues. Handb. Exp. Pharmacol. 195:251-294.

Rhyner K., Egli F., Niemoller M., Wieczoreck A., Greminger P. \& Vetter W. 1989. Serum erythropoietin levels in various diseases. Nephron 51(Suppl.1):39-46.

Scarth J.P., Seibert C., Brown P.R., Teale P., Beamon G.J., Pearce C.M. \& Sams R.A. 2011. UPLC-MS/MS Method for the identification of recombinant human erythropoietin analogues in horse plasma and urine. Chromatographia 74:593-608.

Souillard A., Audran M., Bressolle R., Gareau R., Duvallet A. \& Chanal J.L. 1996a. Pharmacokinetics and pharmacodynamics of recombinant human erythopoietin in athletes: Blood sampling and doping control. Brit. J. Clin. Pharmacol. 42(3):355-364.

Souillard A., Audran M., Bressolle F., Jaussaud P. \& Gareau R. 1996b. Pharmacokinetics and haematological parameters of recombinant human erythropoietin after subcutaneous administrations in horses. Biopharm. Drug Dispos. 17:805-815.

Schwarzwald C. \& Hinchcliff K.W. 2004. Recombinant human erythropoietin as a cause of non-regenerative anemia in a stable of racing thoroughbreds. Proc. 50 ${ }^{\text {th }}$ Convent. Am. Assoc. Equine Pract., p.270-271.

Wen D., Boissel J.P.R., Tracy T.E., Gruniger R.H., Mulcahy L.S., Czelusniak J., Goodman M. \& Bunn H.F. 1993. Erythropoietin structure-function relationships: High degree of sequence homology among mammals. Blood 82(5):1507-1516.

Wickler S.J. \& Anderson T.P. 2000 Hematological changes and athletic performance in horses in response to high altitude $(3,800 \mathrm{~m})$. Am. J. Physiol. Regul. Integr. Comp. Physiol. 279:R1176-R1181.

Woods P.R., Campbell G. \& Cowell R.L. 1997. Non-regenerative anemia associated with administration of recombinant-humanerythropoietin to a Thoroughbred racehorse. Equine Vet. J. 29:326-328. 